\title{
USE OF CYSTATIN C DETERMINATION IN CLINICAL DIAGNOSTICS
}

\author{
Jan Mareša, David Stejskal ${ }^{\mathrm{b}}$, Jitka Vavrouškovác, \\ Karel Urbánek ${ }^{\mathrm{a}}$, Roman Herzig ${ }^{\mathrm{a}}$, Petr Hluštík ${ }^{\mathrm{a}}$
}

\author{
a Clinic of Neurology, Teaching Hospital, Olomouc \\ Department of Laboratory Medicine, Hospital Šternberk \\ Department of Neurology, Hospital Šternberk
}

Received: October 21, 2003; Accepted (with revisions): December 10, 2003

Keywords: Cystatin C / Biochemical diagnostics / Alzheimer's dementia / Early atherosclerosis / Vascular aneurysms / Hyperhomocysteinaemia / Neurodegenerative diseases

This paper presents a current view of the possible clinical uses of cystatin $\mathrm{C}$ determination. Cystatin $\mathrm{C}$ is an inhibitor of cysteine proteases, and relatively stable in the systemic circulation it is comparatively easily determined. Although in clinical practice it is known primarily as a relatively reliable and endogenous marker for glomerular filtration, lately cystatin $\mathrm{C}$ analysis has been discussed in connection with the diagnostics of a variety of diseases such as early atherosclerosis, Alzheimer's dementia, vascular aneurysms, hyperhomocysteinaemia and other neurodegenerative diseases.

\section{INTRODUCTION}

Proteolytic enzymes play, ceteri paribus, an important role in the organism in the processes of food digestion, complement activation and blood coagulation. The effects of these enzymes are controlled by protease inhibitors, such as cystatin C. Increasing interest in these inhibitors results from the finding that uncontrolled proteolysis can lead to irreversible damage such as chronic inflammation, lung damage, malignant growth and also likely to early atherosclerosis.

Cystatin C, previously called post-gamma or gammatrace has a molecular weight of $13 \mathrm{kDa}$ and constitutes $2 \%$ to $4 \%$ of cerebrospinal fluid (CSF) protein. It is a protein belonging to the so-called "cystatin super-family". It is formed of a chain of 120 amino-acids and is produced by a majority of nuclear cells. The gene for cystatin $\mathrm{C}$ synthesis is located on chromosome 20. Cystatin C occurs in the systemic circulation in high concentrations and is considered an important extracellular inhibitor of cysteine proteases with an additional significant antiviral activity. Its concentration in the CSF is 5.5-times higher than in the serum. Non negligible levels are also found in saliva and sperm ${ }^{7}$. If CSF is stored at room temperature, this protein can cleave, lose a fraction of its amino-acids (amino-acid chains) and change its electrophoretic mobility (the speed of migration during electrophoresis) through becoming more acidic. It then travels into the gamma region and this can lead to an erroneous interpretation of the electrophoretic profile although no specific immunostaining of $\operatorname{IgG}$ has been performed to date.

Cystatin $\mathrm{C}$ has been localized in the cytoplasm of brain neurons and also in the adrenal medulla, in the thyroid gland, in the anterior pituitary lobe and in A-cells of the pancreas ${ }^{15}$. It has a prominent blocking effect on cysteine proteases similar to papain and cathepsin $\mathrm{B}, \mathrm{H}$ and L. (Two further inhibitors of these enzymes have been recognized in mammals, namely, cystatin A and B. Owing to the close similarity in structure and activity among these cystatins, post-gamma has been called cystatin C). It can probably influence cysteine protease activity in a controlled manner. This protein is connected to a rare disease occurring only in Iceland: hereditary brain amyloid angiopathy manifesting in adulthood between the ages of 20 and 30 with recurring brain bleeding leading finally to death. The disease is caused by a mutation that changes the amino-acid sequence of cystatin $\mathrm{C}$ via replacement of glutamine with leucine at position 68 . The protein thus becomes amyloid and is stored in the wall of small cerebral vessels, where it can be demonstrated with cystatin $C$ antiserum. In these patients, as well as in patients at risk, the CSF concentrations of cystatin $\mathrm{C}$ are diminished. Lower cystatin $\mathrm{C}$ concentrations in certain tissues of the systemic circulation result in, for example amyloid precipitation in cerebral vessels, in cerebral bleeding, accelerated atherosclerosis, etc.

\section{Cystatin C determination}

Cystatin $\mathrm{C}$ is commonly determined in biological material via three methods. ELISA - has the advantage of measuring low concentrations. Its disadvantage is the impossibility of statim testing. Nephelometry and turbidimetry can be performed statim but in this case, low concentrations cannot be tested. The disadvantages of turbidimetry are its low robustness and low calibration stability. Nephelometry is considered the best technique in this area. 


\section{Clinical uses of cystatin $C$ determination}

Cystatin $\mathrm{C}$ has lately been discussed predominantly in connection with its current or conceived use in the laboratory diagnosis of a variety of diseases:

1. Assessment of glomerular filtration - cystatin $\mathrm{C}$ concentration is considered an excellent correlate of the level of glomerular filtration that is not significantly influenced by other effects (diet, infections, liver function, malignancies, myopathies, body fat content). Typical is its constant production and elimination via glomerular filtration when it is freely filtered in the glomerules and completely reabsorbed in proximal tubular cells of the kidney. An indicator of glomerular filtration used to date - creatinine, in practice is only a rough estimate because it reflects changes with low sensitivity and specificity. Its value depends on muscular mass and thus it depends on age and sex, tubular secretion (changeable intra- and interindividually), urine collection levels and analytical measurement problems (non-specific Jaffé chromogens). It has been demonstrated that cystatin $\mathrm{C}$ level increases even with creatinine clearance decrease below $1.57 \mathrm{ml} . \mathrm{s}^{-1}$ when the creatinine level has not yet changed. It is also possible to use the ratio of serum beta-2-microglobulin/ cystatin $\mathrm{C}$ to differentiate increased lymphoproliferation from deteriorating glomerular filtration. In recent years, many studies have been published using cystatin $\mathrm{C}$ measurements to assess glomerular filtration $(\mathrm{GF})^{4,10,12,14}$ Cystatin $\mathrm{C}$ determination is given preference for its above mentioned independence of a variety of genetic and behavioral factors and its constant production and elimination via glomerular filtration. Study results regarding the diagnostic validity of cystatin $\mathrm{C}$ are sometimes contradictory as some authors hold that cystatin $\mathrm{C}$ has the highest diagnostic value for the assessment of glomerular filtration (ROC analysis). According to some researchers a cystatin $\mathrm{C}$ increase has an almost $100 \%$ specificity and sensitivity for decreased GF. In contrast, same authors state that the specificity and sensitivity of creatinine measurement decreased GF is under $50 \%$. Moreover, cystatin $\mathrm{C}$ show no increases significantly with a decrease as small as $\mathrm{GF}<1.6 \mathrm{ml} . \mathrm{s}^{-1}$ when serum creatinine levels change. The critical difference for repeated cystatin $\mathrm{C}$ measurement is around $37 \%$ (for creatinine around $14 \%$ ). For these reasons, some authors do not recommend using cystatin C, e.g., in patients with incipient nephropathy ${ }^{31}$. Other studies also target the generally accepted stability of cystatin $\mathrm{C}$ in the case of other diseases as increased cystatin $\mathrm{C}$ levels have been observed in a range of tumors or in tissues with abnormal growth ${ }^{17}$.

Despite the above mentioned discrepancies, cystatin $\mathrm{C}$ determination has been found useful and is generally recommended in persons in whom it is not possible for different reasons to examine creatinine clearance (paediatric populations, impossibility of urine collection, etc.). Furthermore, in neonates where cystatin $\mathrm{C}$, in contrast to creatinine, does not cross the fetoplacental barrier, in patients after renal transplantation, patients with liver cirrhosis ${ }^{13}$ or after liver transplantation (determination of endogenous creatinine clearance fails because of lower muscle mass), in women with pre-eclampsia or in diabetics and in some patients with malignancies (e.g., myeloma). According to ROC analysis, cystatin $\mathrm{C}$ determination is in these cases preferred to creatinine ${ }^{1-3,25,26,28-30,32}$.

2. Vascular aneurysms - atherosclerotic and abdominal aortal aneurysms are usually inflammatory processes in which extensive degradation of extracellular matrix and remodelling of vessel wall are found. In these cases, matrix metalloproteinases, serine proteases, as well, as cathepsins probably play a role (in the presence of pro-inflammatory cytokines, cultures of smooth muscle cells produce active cathepsin, leading to degradation of extracellular elastin). However, normal vascular smooth muscle cells produce cystatin $\mathrm{C}$ as well and this prevents aggressive activity of cathepsins against the vessel wall. It has been found that some atherosclerotic plaques and aneurysms do not contain cystatin C. Serum cystatin C concentration was negatively correlated to abdominal aorta aneurysm size and expansion (patients with aneurysms had very low cystatin $\mathrm{C}$ levels ${ }^{27}$ ). According to one study, the specificity of cystatin $\mathrm{C}$ for aneurysm detection is $61 \%$, specificity $57 \%$ (ref. $^{8}$ ).

3. Hyperhomocysteinemia - cystatin $\mathrm{C}$ concentration in people with normal GF level is an independent predictor of homocysteine level when fasting as well as after methionine load (in contrast to serum creatinine level ${ }^{21,24}$ ).

4. Lymphoproliferative diseases - the ratio of serum $\beta_{2}$-microglobulin ( $\left.\mathrm{B}-2-\mathrm{M}\right) /$ cystatin $\mathrm{C}$ is considered a good indicator of lymphoproliferative diseases as its increase reflects decreased glomerular filtration as well.

According to recent studies, further areas for the use of cystatin $\mathrm{C}$ determination in diagnosis and treatment are:

1. Alzheimer's disease

Cystatin $\mathrm{C}$ is, according to current knowledge, considered an amyloidogenic protein, occurring together with beta-amyloid in the walls of the cerebral arterioles in Alzheimer's disease patients, where it is assumed that cystatin leads to neuronal damage. In some patients with this disease, polymorphism of cystatin C gene is claimed to increase the risk of Alzheimer's disease and lower serum cystatin $\mathrm{C}$ levels have been found ${ }^{6,11,19,20}$.

2. Leukoencephalopathy with progressive dementia Cystatin $\mathrm{C}$ participates in neuronal degeneration and reparation of the central nervous system. In the brain it probably inhibits astrocytic activity of cathepsin $\mathrm{L}$ which together with cathepsin S are to key components for regulation of the immune potential of astrocytes and microglia ${ }^{22}$. Patients with this disease have very low concentrations of cystatin $\mathrm{C}$ in the CSF as well as systemic circulation. Cystatin $\mathrm{C}$ accumulates in reactive astrocytes even prior to amyloid formation and the disease manifests through innate cerebral hemorrhage and amyloidosis ${ }^{3}$.

3. Impairment of the blood-CSF barrier Cystatin $\mathrm{C}$ use is discussed as another indicator of blood-CSF barrier impairment. In this regard the de- 
crease in CSF cystatin $\mathrm{C}$ in bacterial meningitis is noted ${ }^{9}$.

4. Degenerative diseases of the retina

Cystatin $\mathrm{C}$ has been found in the retina as well, where it probably has an inhibitory effect on cathepsin $\mathrm{S}$ in retinal pigment epithelium and influences cathepsin D-caused proteolysis. In some patients, reduction in serum concentration of cystatin $\mathrm{C}$ cannot be ruled out $^{23}$.

5. Bone remodelling

Cystatin $\mathrm{C}$ has been found extracellularly in the surrounding of resorption lacunae and intracellularly in osteoclasts. Its function there is probably regulation of bone matrix degradation by cathepsin $\mathrm{K}$. However, no connection between serum cystatin $\mathrm{C}$ concentration and bone remodelling has been found to date ${ }^{18}$.

According to the present results of major studies, cystatin $\mathrm{C}$ determination could contribute to the diagnosis and treatment of a spectrum of diseases and it could become significant marker in clinical diagnosis.

\section{ACKNOWLEDGEMENT}

Supported in part by grant of IGA MH Czech Republic, number NF7480-3/2003: Use of cystatin C determination in a group of patiens with neurodegenerative disease.

\section{REFERENCES}

1. Gerbes AL, Gulberg V, Bilzer M, Vogeser M. (2002) Evaluation of serum cystatin $C$ concentration as a marker of renal function in patients with cirrhosis of the liver. Gut 50, 106-109.

2. Strevens H, Wide-Swensson D, Grubb A. (2001) Serum cystatin C is a better marker for preeclampsia than serum creatinine or serum urate. Scand J Clin Lab Invest 61, 575-580.

3. Izumihara A, Ishihara T, Hoshii Y, Ito H. (2001) Cerebral amyloid angiopathy associated with hemorrhage: immunohistochemical study of 41 biopsy cases. Neurol Med Chir (Tokyo) 41, 471-477, discussion 477-478.

4. Hermida J, Romero R, Tutor JC. (2002) Relationship between serum cystatin $\mathrm{C}$ and creatinine in kidney and liver transplant patients. Clin Chim Acta 316, 165-170.

5. Aronica E, van Vliet EA, Hendriksen E, Troost D, Lopes da Silva FH, Gorter JA. (2001) Cystatin C, a cysteine protease inhibitor, is persistently up-regulated in neurons and glia in a rat model for mesial temporal lobe epilepsy. Eur J Neurosci 14, 1485-1491.

6. Beyer K, Lao JI, Gomez M, Riutort N, Latorre P, Mate JL, Ariza A. (2001) Alzheimer's disease and the cystatin C gene polymorphism: an association study. Neurosci Lett 315, 17-20.

7. Lie MA, Loos BG, Henskens YM, Timmerman MF, Veerman EC, van der Velden U, van der Weijden GA. (2001) Salivary cystatin activity and cystatin $\mathrm{C}$ in natural and experimental gingivitis in smokers and non-smokers. J Clin Periodontol 28, 979-984.

8. Lindholt JS, Erlandsen EJ, Henneberg EW. (2001) Cystatin C deficiency is associated with the progression of small abdominal aortic aneurysms. Br J Surg 88, 1472-1475.

9. Davidsson P, Paulson L, Hesse C, Blennow K, Nilsson CL. (2001) Proteome studies of human cerebrospinal fluid and brain tissue using a preparative two-dimensional electrophoresis approach prior to mass spectrometry. Proteomics 3, 444-452
10. Galteau MM, Guyon M, Gueguen R, Siest G. (2001) Determination of serum cystatin $\mathrm{C}$ : biological variation and reference values. Clin Chem Lab Med 39, 850-857.

11. Deng A, Irizarry MC, Nitsch RM, Growdon JH, Rebeck GW. (2001) Elevation of cystatin C in susceptible neurons in Alzheimer's disease. Am J Pathol 159, 1061-1068.

12. Bokenkamp A, Dieterich C, Dressler F, Muhlhaus K, Gembruch U, Bald R, Kirschstein M. (2001) Fetal serum concentrations of cystatin $\mathrm{C}$ and beta2-microglobulin as predictors of postnatal kidney function. Am J Obstet Gynecol 185, 468-475.

13. Takeuchi M, Fukuda Y, Nakano I, Katano Y, Hayakawa T. (2001) Elevation of serum cystatin C concentrations in patients with chronic liver disease. Eur J Gastroenterol Hepatol 13, 951-955.

14. Risch L, Blumberg A, Huber AR. (2001) Assessment of renal function in renal transplant patients using cystatin C. A comparison to other renal function markers and estimates. Ren Fail 23, 439-448.

15. Reiber H. (2001) Dynamics of brain-derived proteins in cerebrospinal fluid. Clin Chim Acta 310, 173-186.

16. Steinhoff T, Moritz E, Wollmer MA, Mohajeri MH, Kins S, Nitsch RM. (2001) Increased cystatin $C$ in astrocytes of transgenic mice expressing the K670N-M671L mutation of the amyloid precursor protein and deposition in brain amyloid plaques. Neurobiol Dis $8,647-654$.

17. Oddoze C, Morange S, Portugal H, Berland Y, Dussol B. Cystatin C is not more sensitive than creatinine for detecting early renal impairment in patients with diabetes.

18. Yamaza T, Tsuji Y, Goto T, Kido MA, Nishijima K, Moroi R, Akamine A, Tanaka T. (2001) Comparison in localization between cystatin $\mathrm{C}$ and cathepsin $\mathrm{K}$ in osteoclasts and other cells in mouse tibia epiphysis by immunolight and immunoelectron microscopy. Bone 29, 42-53.

19. Roks G, Cruts M, Slooter AJ, Dermaut B, Hofman A, Van Broeckhoven C, Van Duijn CM. (2001) The cystatin C polymorphism is not associated with early onset Alzheimer's disease. Neurology 57, 366-367.

20. Maruyama H, Izumi Y, Oda M, Torii T, Morino H, Toji H, Sasaki K, Terasawa H, Nakamura S, Kawakami H. (2001) Lack of an association between cystatin $\mathrm{C}$ gene polymorphisms in Japanese patients with Alzheimer's disease. Neurology 57, 337-339.

21. Han H, Dwyer JT, Selhub J, Jacques PF, Houser RF, Park JH, Kim YS, Bang BK, Kim S, Jung KA, Chang YK, Bostom AG. (2001) Serum cystatin C is an independent predictor of total homocysteine levels in stable Korean renal transplant recipients with normal serum creatinine. J Ren Nutr 11, 149-154.

22. Gresser O, Weber E, Hellwig A, Riese S, Regnier-Vigouroux A. (2001) Immunocompetent astrocytes and microglia display major differences in the processing of the invariant chain and in the expression of active cathepsin L and cathepsin S. Eur J Immunol 31, $1813-1824$

23. Wasselius J, Hakansson K, Johansson K, Abrahamson M, Ehinger B. (2001) Identification and localization of retinal cystatin C. Invest Ophthalmol Vis Sci 42, 1901-1906.

24. Aras O, Tsai MY, Hanson NQ, Bailey R, Rao G, Hunninghake DB. (2001) Cystatin $C$ is an independent predictor of fasting and postmethionine load total homocysteine concentrations among stable renal transplant recipients. Clin Chem 47, 1263-1268.

25. Finney H, Williams AH, Price CP. (2001) Serum cystatin C in patients with myeloma. Clin Chim Acta 309, 1-6.

26. Booth DR, Tan SY, Booth SE, Tennent GA, Hutchinson WL, Hsuan JJ, Totty NF, Truong O, Soutar AK, Hawkins PN, Bruguera M, Caballeria J, Sole M, Campistol JM, Pepys MB. (1996) Hereditary Hepatic and Systemic Amyloidosis Caused by a New Deletion/Insertion Mutation in the Apolipoprotein AI Gene J Clin Invest 97, 2714-2721.

27. Shi GP, Sukhova GK, Grubb A, Ducharme A, Rhode LH, Lee RT, Ridker PM, Libby P, Chapman HA. (1999) Cystatin C deficiency in human atherosclerosis and aortic aneurysms. J Clin Invest 104, $1167-8$. 
28. Randers E. Cystatin C in sera of patients with acute infections disease with high CRP Citation in: Laboratory Med. 1998, XXVI Nordic Congress of CC, Turku 1998

29. Harmoinen A. Serum cystatin $C$ as a marker for GFR in patients with NIDDM. Citation in: Laboratory Med., XXVI Nordic Congress of of CC, Turku 1998.
30. Stickle D. Correlation of plasma concentrations of cystatin C and creatinine to inulin clearance in a pediatric population Clin. Chem., 1998, 44, 1334-1338.

31. Keevil BG. (1998) Biological variation of cystatin C. Clin. Chem. 44, 1535-1539.

32. Steck AJ, Hartung HP, Kieseier BC. Demyelinisierende Erkrankungen. Darmstadt: Steinkopf Verlag 2003. 